OPEN ACCESS

Edited by:

Alessandro Antonelli,

University of Pisa, Italy

Reviewed by:

Giusy Elia,

University of Pisa, Italy

Anthony Martin Gerdes,

New York Institute of Technology,

United States

Leonidas H. Duntas,

National University of Athens, Greece

*Correspondence:

Vittorio Unfer

vunfer@gmail.com

Specialty section: This article was submitted to

Thyroid Endocrinology,

a section of the journal

Frontiers in Endocrinology

Received: 01 February 2021

Accepted: 12 April 2021

Published: 10 May 2021

Citation:

Benvenga S, Nordio M, Laganà AS and Unfer V (2021)

The Role of Inositol in Thyroid

Physiology and in Subclinical Hypothyroidism Management.

Front. Endocrinol. 12:662582. doi: 10.3389/fendo.2021.662582

\section{The Role of Inositol in Thyroid Physiology and in Subclinical Hypothyroidism Management}

\author{
Salvatore Benvenga ${ }^{1,2}$, Maurizio Nordio ${ }^{2,3}$, Antonio Simone Laganà ${ }^{2,4}$ and Vittorio Unfer ${ }^{2,5 *}$ \\ ${ }^{1}$ Department of Clinical and Experimental Medicine, Section of Endocrinology, University of Messina, Messina, Italy, ${ }^{2}$ The \\ Experts Group on Inositol in Basic and Clinical Research (EGOI), Rome, Italy, ${ }^{3}$ Department of Experimental Medicine, \\ "Sapienza" Università di Roma, Rome, Italy, " Department of Obstetrics and Gynecology, "Filippo Del Ponte" Hospital, \\ University of Insubria, Varese, Italy, ${ }^{5}$ Systems Biology Group Lab, "Sapienza" Università di Roma, Rome, Italy
}

Myo-Inositol (MYO) is the most abundant stereoisomer of inositols' family, cyclic polyols with 6 hydroxyl groups. Myo-Inositol has a relevant role in thyroid function and autoimmune diseases, as a precursor of phosphoinositides that takes part in the phosphatidylinositol (PI) signal transduction pathway. Among phosphoinositides, phosphatidylinositol 4,5- bisphosphate (PIP2) is the precursor of inositol triphosphates (IP3), second messenger of several hormones including thyroid-stimulating hormone (TSH). As a second messenger in the phospholipase $\mathrm{C}$ (PLC)-dependent inositol phosphate $\mathrm{Ca}^{2+}$ /DAG pathway, Myo-Inositol is essential to produce $\mathrm{H}_{2} \mathrm{O}_{2}$ required for the synthesis of thyroid hormones. Consequently, depletion of Myo-Inositol or impaired inositol dependent TSH signaling pathway may predispose to the development of some thyroid diseases, such as hypothyroidism. Many clinical studies have shown that after treatment with Myo-Inositol plus Selenium (MYO+Se), TSH levels significantly decreased in patients with subclinical hypothyroidism with or without autoimmune thyroiditis. The TSH reduction was accompanied by a decline of antithyroid autoantibodies. Moreover, Myo-Inositol supplementation seemed to be involved also in the management of thyroidal benign nodules, with a possible effect in the size reduction. This review proposes a summary of the role of inositol, especially of Myo-Inositol, in the thyroidal physiology and its contribution on the management of some thyroid diseases.

Keywords: myo-inositol, subclinical hypothyroidism, thyroid dysfunctions, TSH, thyroid hormones

\section{INTRODUCTION}

The thyroid gland is responsible for the synthesis and the secretion of thyroid hormones (TH), triiodothyronine (T3) and thyroxine (T4), which is made up by the thyrocytes (epithelial cells that are also named thyroid follicular cells). Of the two hormones, T4 constitutes approximately $90 \%$ of the entire $\mathrm{TH}$ pool, while $\mathrm{T} 3$ makes up the remainder $10 \%$. A peripheral conversion of the prohormone T4 into the biologically more active hormone T3 is made up by enzymes known as deiodinases, which produce around $80 \%$ of the total T3 (1). The deiodinases are homodimeric selenoproteins containing a thioredoxin fold, and classified in three types: type 1 (D1) and type 2 (D2) activate T4 into T3; type 3 (D3) inactivates both hormones (2). Specifically, among the 
activating enzymes, D2 has better catalytic efficiency than D1. $\mathrm{TH}$ circulate in the plasma bound mainly to three proteins: thyroxine-binding globulin (TBG), transthyretin (TTR) and albumin (3). Approximately $5 \%$ of $\mathrm{TH}$ circulate bound to lipoproteins (HDL> LDL> VLDL). Only approximately $0.03 \%$ of circulating $\mathrm{T} 4$ and approximately $0.3 \%$ of circulating $\mathrm{T} 3$ is free, nonprotein-bound (4).

After cell uptake by TH-binding sites on the plasma membrane, $\mathrm{TH}$ reach the nucleus and bind to specific receptors (TR) on the target cells, stimulating or inhibiting gene transcription (5). TH interact with all the biological systems, playing a key role for example in neurological development, in energy metabolism, and in cardiometabolic and reproductive systems.

Myo-inositol (MYO), which is an isoform of inositol, has been shown to play an important role in thyroid physiology. Clinical evidence indicated that patients with impaired thyroid functionality exhibit a higher demand of MYO than healthy subjects (6). MYO altered levels or impaired inositol dependent TSH signaling pathway, may predispose to the development of some alterations in thyroid functionality, such as hypothyroidism, pointing out MYO crucial role in preserving thyroid physiology, in increasing iodine availability and in counteracting its dysfunctions (7).

The aim is to review the role of MYO in the physiology of thyroid function and its potential use in the management of subclinical hypothyroidism (SCH).

\section{MECHANISMS AND KEY FACTORS INVOLVED IN THE SYNTHESIS OF THYROID HORMONES}

$\mathrm{TH}$ biosynthesis occurs at the interface between the follicular lumen and the apical plasma membrane of thyrocytes, and it depends on the interaction of essential components: iodine $\left(\mathrm{I}_{2}\right)$, a $\mathrm{H}_{2} \mathrm{O}_{2}$-dependent peroxidase called thyroperoxidase (TPO), and thyroglobulin ( $\mathrm{Tg}$ ), that works as iodine acceptor.

Iodine homeostasis in thyroid is guaranteed by iodine intake through the diet or food supplements, with a suggested daily intake of $150 \mu \mathrm{g}$ for non-pregnant adults (8), providing values 20 to 50 times higher than the $10 \mu \mathrm{g} / \mathrm{L}$ in the plasma (9). After intestinal adsorption, iodide enters the thyroid through the sodium/iodide symporter (NIS), a transport protein located in the basolateral plasma membrane of thyrocytes, and then it enters in the follicular lumen crossing the apical membrane through a carrier called Pendrin, which shared with NIS a local amino acid sequence homology. Once in the thyroid follicular lumen, iodide is incorporated into the $\mathrm{Tg}$, which is the predominant protein in the thyroid. Human $\mathrm{Tg}$ is a high molecular weight $(660 \mathrm{kDa})$ glycoprotein homodimer $(330 \mathrm{kDa}$ each dimer) containing 66 tyrosine residues, but only up to onefifth of them are iodinated, depending on the availability of dietary iodine.

Another crucial component in TH biosynthesis is the TPO, which is included in transport vesicles, which then merge with the apical plasma membrane of thyrocytes exposing the TPO catalytic site, with the attached heme group, in the thyroid follicular lumen (10). TPO incorporates iodine into Tg using $\mathrm{H}_{2} \mathrm{O}_{2}$ as final electron acceptor. Previous studies underlined that the enzyme responsible for the $\mathrm{H}_{2} \mathrm{O}_{2}$ synthesis is a membranebound NADPH-dependent oxidase (NOX), which exploits $\mathrm{H}_{2} \mathrm{O}_{2}$ as electron acceptor (11). The main system responsible for the $\mathrm{H}_{2} \mathrm{O}_{2}$ generation is composed of dual oxidases 1 and 2 (DUOX1 and 2) that are regulated by two different pathways: DUOX1 is activated by the protein kinase $A$ through the $\mathrm{G}_{\mathrm{s}} \mathrm{PKA}$ pathway; DUOX2 is regulated by protein kinase $C$ through the $\mathrm{G}_{\mathrm{q}^{-}}$phospholipase C (PLC) pathway (12). To mediate the correct production of $\mathrm{H}_{2} \mathrm{O}_{2}$ the DUOX systems require maturation factors, called DUOXA, identified by in silico screening of multiple parallel signature sequencing data bases (13). Defects in DUOX and/or DUOXA represent possible causes of congenital hypothyroidism $(\mathrm{CH})$, confirming the crucial role of the system (14). Besides its central role in TH biosynthesis, $\mathrm{H}_{2} \mathrm{O}_{2}$ is a toxic metabolite, therefore several defense mechanisms contribute in counteracting and avoiding oxidative stress related damages in thyroid (15).

Once all the elements are present at the interface of the follicular lumen and at the apical plasma membrane of thyrocytes, the hormonogenesis process can occur in the follicular lumen.

More specifically, TH synthesis comprises the following steps: 1) oxidation of TPO by $\mathrm{H}_{2} \mathrm{O}_{2} ; 2$ ) oxidation of iodide ions by the $\mathrm{TPO}$; 3) iodination of tyrosyl residues on $\mathrm{Tg}$ to form iodotyrosine moieties; 4) oxidation and coupling of iodotyrosine residues to form the final hormones, T3 and T4.

After the incorporation of oxidized iodide into the Tg, through a process of iodination or iodine organification that generate either monoiodotyrosine (MIT) or diiodotyrosine (DIT) residues, the final step consists in coupling neighboring residues to form the final hormones. Specifically, coupling of two DIT residues yields T4, while coupling of DIT with MIT yields T3. TPO and $\mathrm{H}_{2} \mathrm{O}_{2}$ catalyze the coupling reaction, which is strictly dependent on $\mathrm{Tg}$ structure and leads to Tg-bound THs (Figure 1). A vescicle-mediated endocytosis, also known as micropinocytosis, or macropinocytosis, depending on the physiological circumstances, transports the modified Tg inside the thyrocytes, where MIT, DIT, and TH are released after proteolysis, crossing the basolateral membrane (16).

\section{THE ROLE OF TSH IN THE CONTROL OF THYROID HORMONE SYNTHESIS}

Iodide availably and thyrotropin (or thyroid stimulating hormone, TSH) are the main control mechanisms of TH synthesis. Low iodide availability may lead to inadequate $\mathrm{TH}$ synthesis, while excess iodide may completely inhibit their production. Such protective process, known as Wolff-Chaikoff effect, seems to inhibit $\mathrm{H}_{2} \mathrm{O}_{2}$ production and consequently $\mathrm{Tg}$ iodination.

TSH controls various steps of the synthesis and release of TH, starting from stimulating the NIS-mediated iodide uptake by the 


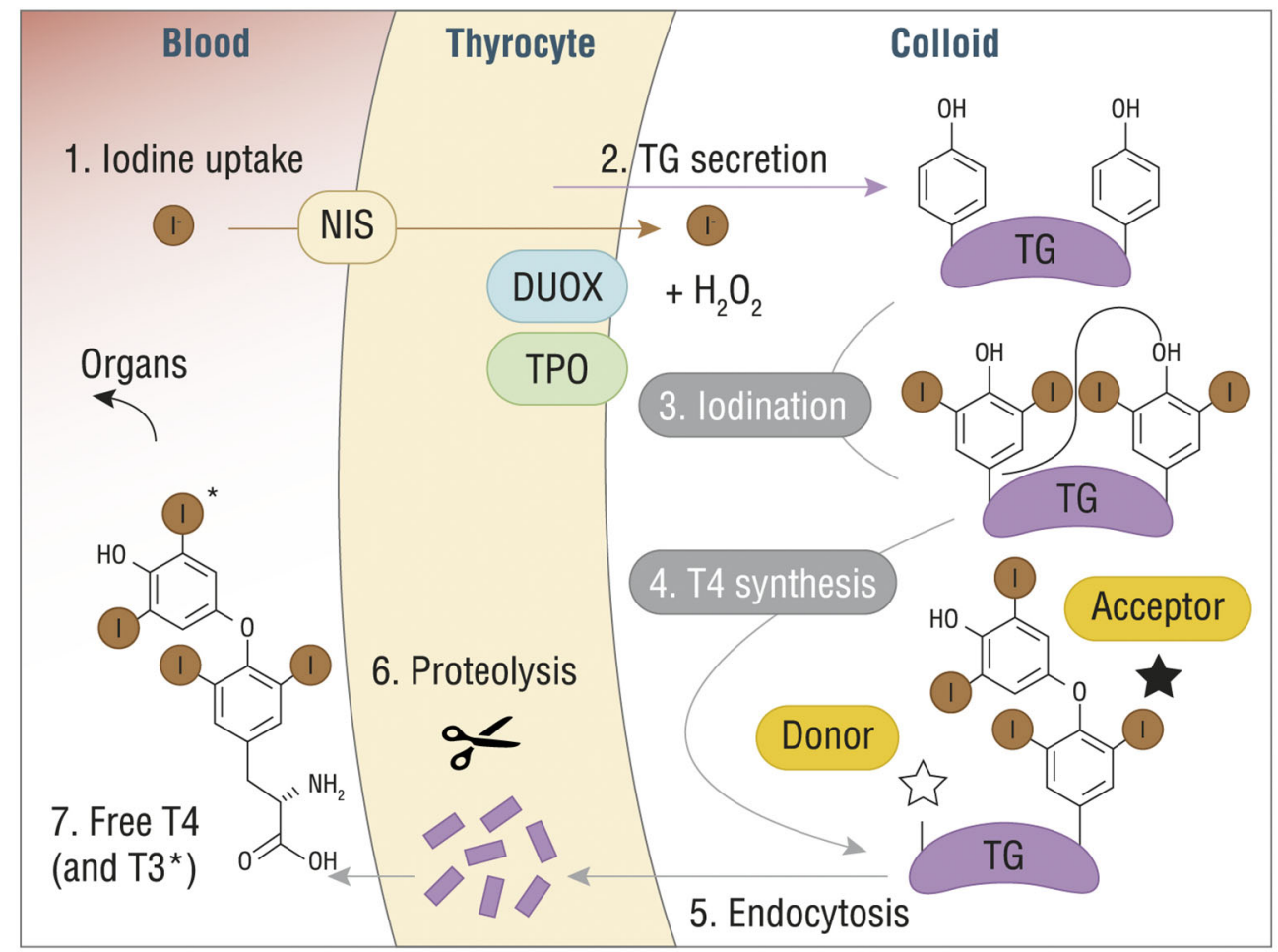

FIGURE 1 | T4 (or T3) synthesis from Tg in thyroid gland. DUOX, dual oxidase; $\mathrm{H}_{2} \mathrm{O}_{2}$, hydrogen peroxide; I', iodine; NIS, sodium/iodide symporter; T3, triiodothyronine; T4, thyroxine; TG, thyroglobulin. Reproduced with the permission from "The structure of human thyroglobulin." Coscia F. et al., Nature 578.7796 (2020): 627-630 (License No 4998080013478).

thyrocytes. TSH is synthesized by the anterior pituitary, under the stimulus of the thyrotropin-releasing hormone (TRH), which is secreted by the hypothalamus in a negative feedback system (17).

TSH stimulates TH synthesis by binding to its receptor (TSHR), which is expressed in the basolateral membrane of thyrocytes. TSHR is a G protein-coupled receptor (class A) that belongs to the sub-family of the glycoprotein hormone receptors (GPHRs), along with the gonadotropin receptors: the follicle-stimulating hormone receptor (FSHR) and the luteinizing hormone/ choriogonadotropin receptor (LHCGR). Upon TSH binding, TSHR activates different $G$ protein subtypes and signaling pathways, among which $\mathrm{G}_{\mathrm{s}^{-}}$and $\mathrm{G}_{\mathrm{q}}$-induced signaling are probably the most important (18). $\mathrm{G}_{\mathrm{s} \alpha}$ signaling involves the activation of the adenylate cyclase, with production of cyclic adenosine monophosphate that phosphorylates protein kinase A (PKA). The pathway controls the expression of NIS, Tg, TPO and TSHR, through thyroid-specific transcription factors (19), and regulates Tg macrocytosis and internalization (20). $\mathrm{G}_{\mathrm{q} / 11}$ signaling encompasses the activation of PLC-dependent inositol phosphate $\mathrm{Ca}^{2+} / \mathrm{DAG}$ pathway, which leads to increased iodination through the release of inositol triphosphate (IP3) $(21,22)$. IP3, indeed, is responsible for the $\mathrm{Ca}^{2+}$ release from the endoplasmic reticulum, which is necessary for the activation of DUOX/DUAOXA2 system and the synthesis of $\mathrm{H}_{2} \mathrm{O}_{2}$ (Figure 2).
The two pathways are activated in separate moments, as they require different TSH concentrations. The cAMP signaling is 100 times more efficient to transmit the TSH signal than the inositol pathway. This is confirmed by an in vitro experiment on kidney embryonal cells expressing THSR (HEK-TSHR cells), where the authors demonstrate that the $\mathrm{EC}_{50}$ required to activate the cAMP signaling is $0.75 \mathrm{mU} / \mathrm{mL}$, while $\mathrm{EC}_{50} \geq 71 \mathrm{mU} / \mathrm{mL}$ is necessary for the inositol pathway (24). The presence of two binding sites on TSHR, with different affinity for TSH, explains such different behavior. The high-affinity site binds to TSH molecules at lower concentrations, activating the cAMP pathway; the low-affinity site binds to TSH at much higher concentrations and activates the inositol pathway (25).

\section{SUBCLINICAL HYPOTHYROIDISM}

TSH is the leading, and sometimes the sole, diagnostic parameter that physicians use to evaluate the thyroid function.

Hypothyroidism is a condition where the thyroid functionality is lower than normal, and exists in two forms, overt and subclinical (SCH). The former is characterized by levels of TSH above the upper normal limit and low concentrations of THs, indicating thyroid insufficiency. On the other hand, SCH features TSH levels above the upper normal limit, but levels of $\mathrm{TH}$ within the normal 


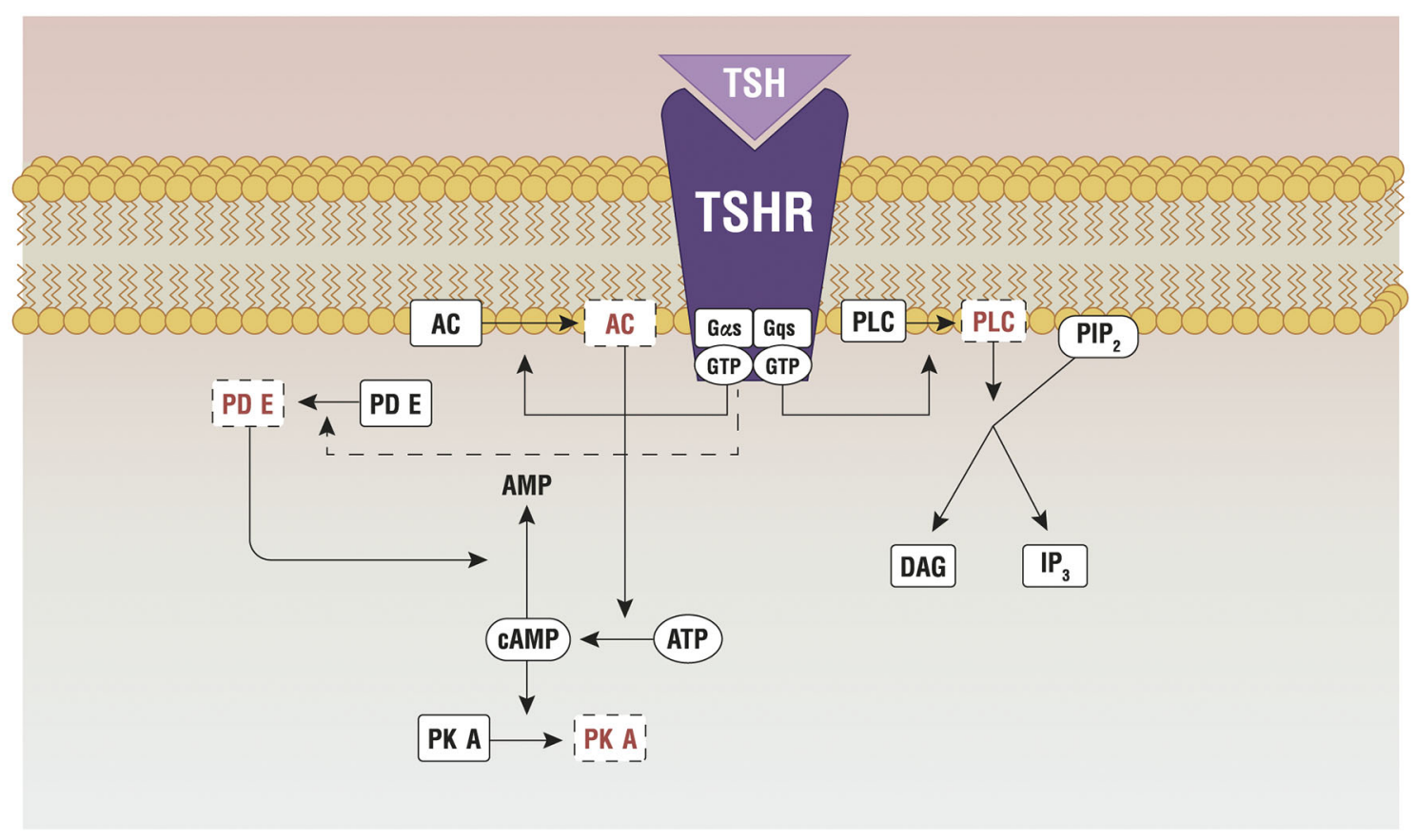

FIGURE 2 | Principal pathways active by the TSH-TSHR binding. AC, adenylate cyclase; AKT, protein kinase B; ATP, adenosine triphosphate; cAMP, cyclic adenosine monophosphate; Gos/Gqs, G protein; GTP, guanosine triphosphate; IP3, inositol triphosphate; mTOR, protein kinase (mammalian target of rapamicin); PDE, phosphoesterase; PIP2, phosphatidylinositol 4,5- biphosphate; PKA, protein kinase A; PLC, phospholipase C; TSHR, TSH Receptor; TSH, thyroid stimulating hormone. Reproduced with the permission from Benvenga et al. (23) (License No 4997560949993).

range. This normality of TH levels occurs because small fluctuations of free levothyroxine (fT4) levels, although in a range that is normal for the population sampled to construe a reference range (but that it is less wide for any given individual), trigger the hypothalamicpituitary-thyroid axis so as to increase the secretion of TSH (26). Scientists revised the upper physiological TSH limit multiple times over the years; for instance, it is $4,5 \mathrm{mIU} / \mathrm{mL}$ according to the National Health and Nutrition Examination Survey (NHANES III) $(27,28)$. SCH with TSH above this threshold can be divided in two types: grade 1, with TSH $<9.9 \mathrm{mIU} / \mathrm{mL}$ TSH; and grade 2, with $\mathrm{TSH} \geq 10 \mathrm{mUI} / \mathrm{mL}$ (28).

$\mathrm{SCH}$ is a common condition especially in women, with a prevalence higher than $20 \%$ in subjects over 75 years (29). Autoimmune thyroid diseases (AITDs) are the main cause of $\mathrm{SCH}$, with Hashimoto thyroiditis (HT) being the most common. In fact, HT occurs in approximately $5 \%$ of the Caucasian population and it is associated to $10-15 \%$ of SCH cases (30). Furthermore, $\mathrm{SCH}$ is at risk of progression to the overt form.

Also, long term effects of SCH are numerous and may involve many organic systems, with cardiometabolic, neurological, renal and reproductive issues. Indeed, SCH is associated with increased relative risk (RR) of cardiovascular disease (CVD) of around 1.33 (95\% CI, 1.14-1.54). RR for the all-cause mortality is equally increased in patients with SCH (RR: 1.20; 95\% CI, 1.07-1.34) (31). Hypothyroidism is also the second cause of dyslipidemia, characterized by elevated levels of low-density lipoprotein (LDL), cholesterol and triglyceride (32). SCH patients might also exhibit a major exposure to the development of nonalcoholic fatty liver disease (NALFD) (33), and reproductive issues. Female teenagers with thyroid problems are 4 times more likely to develop menstrual cycle disorders than their healthy peers. In particular, menstrual disturbances affect around $10.2 \%$ of SCH patients (34). A high TSH levels may also alter the ovarian reserve, thus reducing fertility (35). Moreover, elevated TSH seems to correlate with negative outcomes in pregnancy, increasing the rate of miscarriages and preterm births $(36,37)$.

Despite these long-term risks, the management of SCH still remains highly debated. The standard pharmacological treatment for hypothyroidism is based on levothyroxine (synthetic T4), due to its efficacy, long-term benefits, and good adsorption (38). However, some patient subgroups referred a slight preference for the combined therapy based on L-thyroxine and Ltriiodothyronine (T3) (39), opening still unresolved issues in the management of hypothyroidism. Indeed, common variations in the gene codifying for the deiodinase type 2 may be responsible for both poorer psychological well-being on T4 monotherapy and improved response to combined T4/T3 therapy in patients on thyroid hormone replacement (40). On the other hand, studies comparing monotherapy with combined therapy, pointed out that subjects were unable to distinguish treatment and although as many as $18 \%$ preferred the combined approach, there was a relatively high incidence of side effects among those using the combination, making the topic more controversial $(41,42)$. In addition, as reported in the international guidelines drawn up by 
the American Thyroid Association Task Force on Thyroid Hormone Replacement, there is no consistently strong evidence of greater efficacy of the combined therapy over monotherapy with levothyroxine (43), confirming the monotherapy as the mainstay of treating hypothyroidism.

Noteworthy, current practice guidelines, which however produced many controversies, restrict the use of levothyroxine in the SCH to patients with overt hypothyroidism and $\mathrm{TSH}>10$ $\mathrm{mIU} / \mathrm{mL}$. Indeed, one of the most critical problems related to $\mathrm{SCH}$ management, is the over treatment even in those patients for which it is not necessary. Pharmacological treatment of $\mathrm{SCH}$ is recommended only in particular cases, such as women seeking pregnancy and patients with important comorbidities $(38,43$, 44 ), and it should be tailored to the individual patient based on the exposure at specific risk factors.

\section{MYO-INOSITOL}

Inositol, a cyclic polyol with 6 hydroxyl groups, extracted, was isolated for the first time from muscle tissue by Schererer in 1980 (45). Inositols may exist in 9 possible isoforms (46). Myo-inositol (MYO) was the first isoform identified and it is the most abundant (more than 99\%) in the eukaryotic cells (47). Dietary intake is the main source of MYO, either as free form or as phytate (IP6) (48). IP6 is more common in vegetables, while free inositol is more commons in animal sources. Dietary IP6 is metabolized by bacterial phytases (homologous of the mammalian InsP6 phosphatase) to produce free MYO, orthophosphate, and inositol-phosphate derivatives (i.e. mono-, di-, tri-, tetra-, and penta-phosphate esters) $(49,50)$. Fresh fruits, vegetables, beans and cereals are valuable inositol sources. In particular, large amounts of phytates are present in dried nuts, such as almonds, walnuts, and Brazilian nuts (9.4, 6.7 and $6.3 \%$ of dry weight, respectively) (49).

Dietary MYO and derivates are absorbed in the gut through sodium-dependent transporters, called sodium/myo-inositol channels type 1 (SMIT1) and type 2 (SMIT2), which are located in the duodenum and jejunum (51).

The Western diet guarantees a daily intake of around $1 \mathrm{~g}$ of MYO, but the absorption may be affected by a number of factors such as age, use of medications or substances like caffeine $(52,53)$.

Besides dietary intake, MYO is produced endogenously from glucose in two enzymatic steps. A hexokinase transforms glucose into glucose-6-phosphate, which is then converted into myoinositol-1-phosphate. In humans, this endogenous synthesis produces up to $2 \mathrm{~g}$ MYO per day in each kidney, for a daily total of $4 \mathrm{~g}$ (54). Briefly, MYO homeostasis depends on three distinct mechanisms: 1) intestinal absorption and urinary excretion; 2) transport through specific carriers from plasma to interstitial fluid of cells; 3 ) endogenous synthesis and catabolism.

Exogenous administration of MYO in daily dosages of 4-30 g up to 12 months is generally well tolerated. Mild side effects, such as nausea and diarrhea, may appear only for daily dosages greater than $12 \mathrm{~g}$ (55).

Several MYO-containing phospholipids are precursors for the biosynthesis of countless molecular intermediates involved in signaling transduction, including inositol triphosphate
(IP3), inositol phosphates (IP), phosphatidylinositol (PI), phosphatidylinositol-phosphates (PIPs), glycosylphosphatidylinositols (GPIs), inositol-phosphoglycans (IPGs) and inositol ethers and esters (54, 56). Among these, phosphatidylinositol-4,5-biphosphate (PIP2) is the precursor of IP3 and diacylglycerol (DAG), which are involved in the phospholipase C (PLC)-dependent inositol phosphate $\mathrm{Ca}^{2+}$ / DAG, working as second messengers of several hormones including TSH, LH, FSH and insulin (23) (Figure 3).

Therefore, it is not surprising that impaired MYO homeostasis correlate with a wide variety of conditions, including thyroid disorders, polycystic ovary syndrome (PCOS), fertility disorders, diabetes, metabolic, and neurological disorders (57).

Researchers found a correlation between intracellular MYO concentration and systemic TSH. Indeed, in vitro experiments demonstrated that thyrocytes actively accumulate MYO with increasing TSH levels (58). In thyrocytes, TSH dose-dependently stimulates inositol phosphate formation (59), with both the PIP2 cascade and the cAMP cascade controlling the synthesis of thyroid hormones. In the thyroid, imbalances in the inositol metabolism can impair thyroidal hormone biosynthesis, storage and secretion (23). Specifically, MYO regulates the $\mathrm{H}_{2} \mathrm{O}_{2}$ mediated iodination in thyrocytes through the PLC-dependent inositol phosphate $\mathrm{Ca}^{2+} / \mathrm{DAG}$ pathway, resulting in increased $\mathrm{H}_{2} \mathrm{O}_{2}$ generation, which is a crucial step for iodine organification and thyroid hormones biosynthesis. Indeed, $\mathrm{H}_{2} \mathrm{O}_{2}$, generated under the stimulus of MYO, is available for iodine incorporation inside the thyroid $(60,61)$. Differently, the cAMP cascade induced by TSH activity, is more involved in cell growth and differentiation, and in thyroid hormones secretion. Therefore, MYO exerts a crucial role in thyroid physiology, by its function in TSH regulation of iodination and by an increased sensitivity of thyrocytes to TSH. Metabolomic investigations confirmed such evidence, indicating that MYO demand is higher in hypothyroid patients than in healthy subjects (6), making MYO very appealing as a molecule to increase iodine availability counteracting thyroid dysfunctions (7).

\section{MYO-INOSITOL IN THE TREATMENT OF SUBCLINICAL HYPOTHYROIDISM}

MYO is a second messenger in the phospholipase C (PLC)dependent inositol phosphate $\mathrm{Ca}^{2+} / \mathrm{DAG}$ pathway, which leads to the production of $\mathrm{H}_{2} \mathrm{O}_{2}$ required for the synthesis of $\mathrm{TH}$. Consequently, depletion of MYO or impaired inositol-dependent TSH signaling pathway may predispose to the development of hypothyroidism (62). In the last years, a growing interest for the role of MYO in thyroid pathophysiology has fostered new studies on its possible involvement in SCH and AITDs. In 2013, Nordio M. and Pajalich R. investigated the effectiveness of MYO oral treatment in women with AITD-related SCH. Forty-eight participants, with TSH comprised between 4.01 and $9.99 \mathrm{mIU} / \mathrm{L}$ and with positive TPOAb and TgAb, were randomly divided in two equal groups and treated either with $600 \mathrm{mg}$ of MYO plus $83 \mu \mathrm{g}$ of selenium (MYO+Se) or only $83 \mu \mathrm{g}$ of selenium (Se) for 


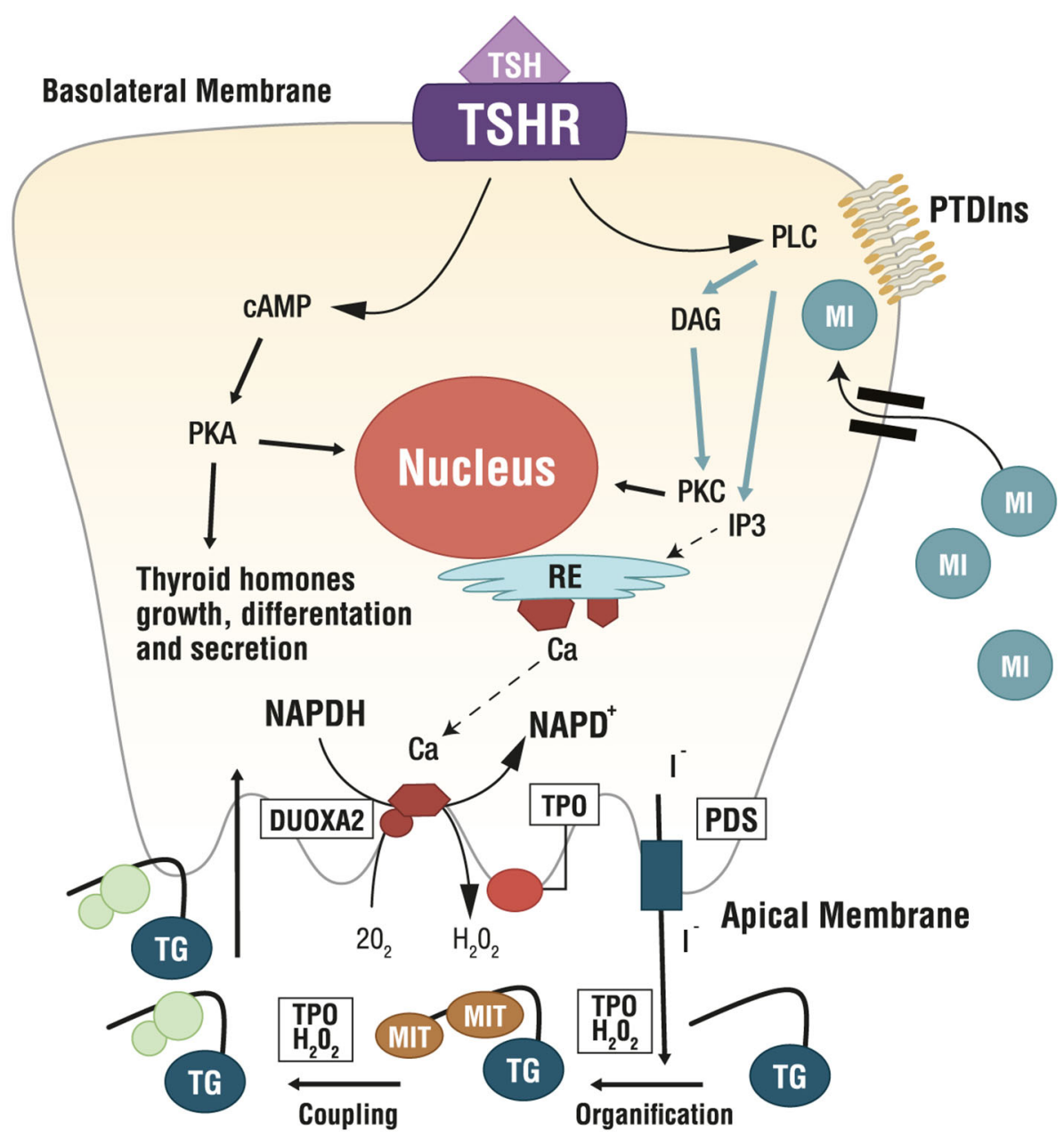

FIGURE 3 | Role of Myo-Inositol in physiology of thyroid. Ca, calcium; cAMP, cyclic adenosine monophosphate; DAG, diacylglycerol; DUOXA2, dual oxidase A 2; $\mathrm{ER}$, endoplasmic reticulum; $\mathrm{H}_{2} \mathrm{O}_{2}$, hydrogen peroxide; I', iodine; IP3, inositol triphosphate; MI, myo-inositol; MIT, monoiodotyrosine; NAPD+/NADPH, nicotinamide adenine dinucleotide phosphate; $\mathrm{O}_{2}$, oxygen; PDS, pendrin; PKA, protein kinase A; PKC, protein kinase C; PLC, phospholipase C; PTDIns, phosphatidylinositol; TG, thyroglobulin; TSH, thyroid stimulating hormone; TSHR, TSH Receptor; TPO, thyreoperoxidase.

6 months. The authors found significant improvements of thyroid parameters in the MYO+Se group at the end of the study: $31 \%$ decrease of TSH $(4.4 \pm 0.9$ vs $3.1 \pm 0.6 \mathrm{mIU} / \mathrm{mL}), 44 \%$ decrease of $\mathrm{TPOAb}$ and $48 \%$ decrease of $\operatorname{TgAb}(\mathrm{p}<0.01$ for each parameter). In contrast, women in the Se group experienced improvement only in the antibody levels, with no change in the TSH level (63). Subsequent studies confirmed these findings. Morgante et al. investigated the prevalence of SCH in insulin resistant PCOS patients and the possible effect of inositol as insulin sensitizer. After 6 months of inositol + metformin treatment, TSH decreased significantly $(4.00 \pm 1.98$ to $2.35 \pm 1.65 \mathrm{mU} / \mathrm{L})$, compared to metformin only (64).

More recent studies evaluated the effect of MYO treatment in a larger cohort of patients. A clinical trial on 86 patients with $\mathrm{SCH}$ and HT, who were treated with $600 \mathrm{mg}$ MYO and $83 \mu \mathrm{g} \mathrm{Se}$ for 6 months, demonstrated a significant improvement in TSH levels $(3.12 \pm 0.09 \mathrm{mIU} / \mathrm{L}$ down from $4.32 \pm 0.06 \mathrm{mIU} / \mathrm{L}$ at baseline; $\mathrm{p} \leq 0.001)$. In addition, these patients reported a significant improvement in their quality of life, evaluated through a subjective symptomatology test (65). Another recent study included 168 patients with HT and TSH level between 3 and $6 \mathrm{mIU} / \mathrm{mL}$. Participants were divided in two groups and treated either with $\mathrm{MYO}+\mathrm{Se}(600 \mathrm{mg}+83 \mu \mathrm{g}$, respectively) or Se $(83 \mu \mathrm{g})$. The authors found a significant improvement in thyroid parameters (TSH, fT4, TPOAb, TgAb) only in the MYO+Se group (66). Taken twice a day, this combined treatment was also effective in reducing TSH levels and the consequent risk to develop SCH (67). In 2018, another study demonstrated the efficacy and the safety of MYO+Se supplementation in pregnancy women. Patients with TSH comprised between 1.6$2.5 \mu \mathrm{IU} / \mathrm{ml}$ were enrolled and were treated with $600 \mathrm{mg} \mathrm{MYO}$ plus $83 \mu \mathrm{g}$ Se, once a day, from the first to third trimester. The results showed a prevention against $\mathrm{SCH}$ thank to the treatment, with a stabilization of TSH, fT3 and fT4 (68). 
Other studies assessed the efficacy of MYO in patients with $\mathrm{SCH}$ and HT, depending on the duration of the treatment, and found that $\mathrm{MYO}+\mathrm{Se}$ supplementation reduced $\mathrm{TSH}$ by $21 \%$ in three months (69). TSH decreased further, and linearly, when treatment duration was extended up to 1 year (62).

Besides improving TSH levels (indicating improved THsynthesis by the thyrocytes), MYO improves thyroid antibody levels, indicating ameliorations of the autoimmune process. HT is characterized by increased levels of Interferon $\gamma($ IFN- $\gamma$ ), which stimulates natural killer cells and lymphocytes CD4+ and CD8+ to secrete CXCL10 cytokine. CXCL10 is an important inflammatory marker for the thyroid, since it causes a strong inflammatory response that damages thyroidal morphology and functionality (70).

$\mathrm{MYO}+$ Se treatment demonstrated in vitro a protective effect on blood mononuclear cells (PBMC) from either HT or healthy patients, stressed with $\mathrm{H}_{2} \mathrm{O}_{2}$. In these experiments, MYO+Se decreased the expression of the cytokines CXCL10, CCL2 and CXCL9, with $80 \%$ reduction of the total cytokines. MYO+Se treatment dose-dependently improved cell vitality and Comet score, thus reducing genotoxicity (71-73).

Recent preliminary metabolomic investigations compared histological thyroid samples of healthy subjects with those of patients with non-malignant nodular diseases, follicular adenoma and thyroid carcinoma, focusing on the potential role of MYO in thyroid nodules. The authors concluded that MYO reduction correlates with increased thyroidal tissue malignancy. The study identified MYO and scyllo-inositol as possible markers for thyroid malignancy (74). A subsequent retrospective study examined the effects of $600 \mathrm{mg}$ MYO supplementation for 6 months on benign nodules [class I and II according to the AACE/ACE/AME Guidelines that outline the risk of malignancy of thyroid lesions (75)] in patients with SCH and HT. The authors found significantly positive results regarding diameter reduction $(16.72 \pm 1.32$ vs $12.44 \pm 1.81)$, number of mixed nodules for patients $(1.39 \pm 0.16$ vs $1.05 \pm 0.15)$ and elasticity $(1.80 \pm 0.13$ vs $1.24 \pm 0.18)(76)$.

\section{CONCLUSION}

Subclinical hypothyroidism (SCH) is a condition of impaired thyroid functionality, which is characterized by TSH levels above the upper physiological limit, but TH levels within the normal range. To date $\mathrm{SCH}$ management still remains a largely debated topic, even though it is a condition at high risk of progression to overt hypothyroidism, further exposing affected patients to many

\section{REFERENCES}

1. Maia AL, Goemann IM, Meyer ELS, Wajner SM. Type 1 Iodothyronine Deiodinase in Human Physiology and Disease. J Endocrinol (2011) 209 (3):283-97. doi: 10.1530/JOE-10-0481

2. Bianco AC, Salvatore D, Gereben B, Berry MJ, Larsen PR. Biochemistry, Cellular and Molecular Biology, and Physiological Roles of the Iodothyronine
TABLE 1 | Effects of inositol on thyroid functionality.

\section{INOSITOL IN THYROID}

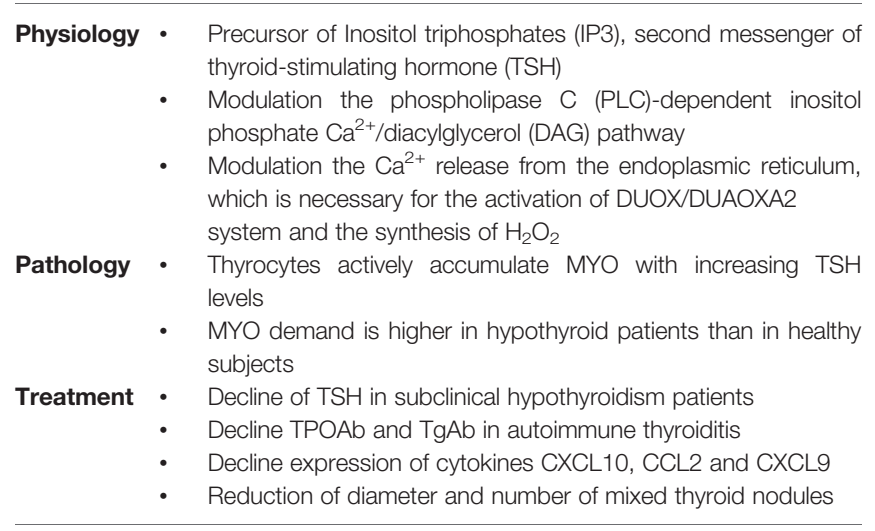

long-term effects. At the same time, the use of pharmacological levothyroxine-based therapy in $\mathrm{SCH}$ is recommended only when it is strictly necessary, since it risks binding patients to a chronic pharmacological approach throughout their life. Therefore, the management of the SCH needs a proper monitoring, tailored to the affected individual patient. In this way, MYO administration results being an intriguing approach. The importance of the physiological role of MYO in the wellbeing of the organism is well recognized. As a precursor of second messengers, such as IP3, MYO supports the proper function of several organs and tissues, including the thyroid (Table 1). Specifically, since its crucial role in TSH regulation of iodination in the process of $\mathrm{TH}$ biosynthesis, MYO physiological levels correlate with a euthyroid condition. Numerous publications indeed demonstrate the beneficial effects of MYO treatment against subclinical hypothyroidism and autoimmune thyroiditis both in vitro and in vivo, pointing out MYO intriguing application in recovering thyroid dysfunctions. Specifically, the up-to-date picture of clinical results here reported, reveal that the supplementation MYO is useful to manage subclinical hypothyroidism conditions. This approach can avoid the progression to the overt hypothyroidism and delay the occurrence of a chronic pharmacological therapy in these patients, extending the therapeutic use of MYO and shaping future clinical studies on $\mathrm{SCH}$ management.

\section{AUTHOR CONTRIBUTIONS}

All authors listed have made a substantial, direct, and intellectual contribution to the work, and approved it for publication.

Selenodeiodinases. Endocr Rev (2002) 23(1):38-89. doi: 10.1210/ edrv.23.1.0455

3. Bartalena L, Robbins J. Variations in Thyroid Hormone Transport Proteins and Their Clinical Implications. Thyroid (1992) 2(3):237-45. doi: 10.1089/ thy.1992.2.237

4. Benvenga S. Thyroid Hormone Transport Proteins and the Physiology of Hormone. In: Braverman LE, Cooper DS, editors. Werner and Ingbar's, The 
Thyroid, 10th ed. Philadelphia: Wolters Kluwer, Lippincott Williams \& Wilkins (2013). p. 93-103.

5. Cheng SY, Leonard JL, Davis PJ. Molecular Aspects of Thyroid Hormone Actions. Endocr Rev (2010) 31(2):139-70. doi: 10.1210/er.2009-0007

6. Piras C, Pibiri M, Leoni VP, Balsamo A, Tronci L, Arisci N, et al. Analysis of Metabolomics Profile in Hypothyroid Patients Before and After Thyroid Hormone Replacement. J Endocrinol Invest (2020). doi: 10.1007/s40618-02001434-y

7. Barbaro D, Orrù B, Unfer V. Iodine and Myo-Inositol: A Novel Promising Combination for Iodine Deficiency. Front Endocrinol (2019) 10:457. doi: $10.3389 /$ fendo.2019.0045710

8. WHO. Assessment of the Iodine Deficiency Disorders and Monitoring Their Elimination. Geneva: WHO (2007). p. 1-107.

9. Rousset B, Dupuy C, Miot F DJ. Chapter 2 Thyroid Homone Synthesis and Secretion (2015). Available at: https://www.ncbi.nlm.nih.gov/books/ NBK285550/.

10. Yokoyama N, Taurog A. Porcine Thyroid Peroxidase: Relationship Between the Native Enzyme and an Active, Highly Purified Tryptic Fragment. Mol Endocrinol (1988) 2(9):838-44. doi: 10.1210/mend-2-9-838

11. Dupuy C, Kaniewski J, Dème D, Pommier J, Virion A. NADPH-Dependent H2O2 Generation Catalyzed by Thyroid Plasma Membranes: Studies With Electron Scavengers. Eur J Biochem (1989) 185(3):597-603. doi: 10.1111/ j.1432-1033.1989.tb15155.x

12. Rigutto S, Hoste C, Grasberger H, Milenkovic M, Communi D, Dumont JE, et al. Activation of Dual Oxidases Duox1 and Duox2: Differential Regulation Mediated by Camp-Dependent Protein Kinase and Protein Kinase CDependent Phosphorylation. J Biol Chem (2009) 284(11):6725-34. doi: $10.1074 /$ jbc.M806893200

13. Grasberger H, Refetoff S. Identification of the Maturation Factor for Dual Oxidase: Evolution of an Eukaryotic Operon Equivalent. J Biol Chem (2006) 281(27):18269-72. doi: 10.1074/jbc.C600095200

14. Moreno JC, Bikker H, Kempers MJ, van Trotsenburg AS, Baas F, de Vijlder JJ, et al. Inactivating Mutations in the Gene for Thyroid Oxidase 2. N Engl J Med (2002) 347(2):95-102. doi: 10.1056/NEJMoa012752

15. Song Y, Driessens N, Costa M, De Deken X, Detours V, Corvilain B, et al. Roles of Hydrogen Peroxide in Thyroid Physiology and Disease. J Clin Endocrinol Metab (2007) 92(10):3764-73. doi: 10.1210/jc.2007-0660

16. Friesema ECH, Grueters PA, Biebermann H, Krude H, Von Moers A, Reeser $\mathrm{M}$, et al. Association Between Mutations in a Thyroid Hormone Transporter and Severe X-Linked Psychomotor Retardation. Lancet (2004) 364 (9443):1435-7. doi: 10.1016/S0140-6736(04)17226-7

17. Chin WW, Carr FE, Burnside J, Darling DS. Thyroid Hormone Regulation of Thyrotropin Gene Expression. Recent Prog Horm Res (1993) 48:393-414. doi: 10.1016/b978-0-12-571148-7.50018-x

18. Kleinau G, Worth CL, Kreuchwig A, Biebermann H, Marcinkowski P, Scheerer P, et al. Structural-Functional Features of the Thyrotropin Receptor: A Class A G-Protein-Coupled Receptor At Work. Front Endocrinol (Lausanne) (2017) 8:86. doi: 10.3389/fendo.2017.00086

19. Tuncel M. Thyroid Stimulating Hormone Receptor. Mol Imaging Radionucl Ther (2017) 26:87-91. doi: 10.4274/2017.26.suppl.10

20. Bernier-Valentin F, Kostrouch Z, Rabilloud R, Rousset B. Analysis of the Thyroglobulin Internalization Process Using In Vitro Reconstituted Thyroid Follicles: Evidence for a Coated Vesicle-Dependent Endocytic Pathway. Endocrinology (1991) 129(4):2194-201. doi: 10.1210/endo-129-4-2194

21. Soundarrajan M, Kopp PA, Case C. Thyroid Disease and Reproduction. Thyroid Dis Reprod (2019) 1-17. doi: 10.1007/978-3-319-99079-8_1

22. Grasberger H, Van Sande J, Mahameed AHD, Tenenbaum-Rakover Y, Refetoff S. Brief Report: A Familial Thyrotropin (Tsh) Receptor Mutation Provides in Vivo Evidence That the Inositol Phosphates/Ca2+ Cascade Mediates TSH Action on Thyroid Hormone Synthesis. J Clin Endocrinol Metab (2007) 92(7):2816-20. doi: 10.1210/jc.2007-0366

23. Benvenga S, Antonelli A. Inositol(s) in Thyroid Function, Growth and Autoimmunity. Rev Endocr Metab Disord (2016) 17(4):471-84. doi: 10.1007/ s11154-016-9370-3

24. Boutin A, Allen MD, Geras-Raaka E, Huang W, Neumann S, Gershengorn MC. Thyrotropin Receptor Stimulates Internalization-Independent Persistent Phosphoinositide Signaling. Mol Pharmacol (2011) 80(2):240-6. doi: 10.1124/ mol.111.072157
25. Allen MD, Neumann S, Gershengorn MC. Occupancy of Both Sites on the Thyrotropin (TSH) Receptor Dimer is Necessary for Phosphoinositide Signaling. FASEB J (2011) 25(10):3687-94. doi: 10.1096/fj.11-188961

26. Biondi B, Cappola AR, Cooper DS. Subclinical Hypothyroidism: A Review. JAMA (2019) 322(2):153-60. doi: 10.1001/jama.2019.9052

27. Hollowell JG, Staehling NW, Dana Flanders W, Harry Hannon W, Gunter EW, Spencer CA, et al. T4, and Thyroid Antibodies in the United States Population (1988 to 1994): National Health and Nutrition Examination Survey (NHANES III). J Clin Endocrinol Metab (2002) 87(2):489-99. doi: 10.1210/jcem.87.2.8182

28. Peeters RP. Subclinical Hypothyroidism. N Engl J Med (2017) 376:2556-65. doi: 10.1056/NEJMcp1611144

29. Redford C, Vaidya B. Subclinical Hypothyroidism: Should We Treat? Post Reprod Health (2017) 23(2):55-62. doi: 10.1177/2053369117705058

30. Pyzik A, Grywalska E, Matyjaszek-Matuszek B, Roliński J. Immune Disorders in Hashimoto's Thyroiditis: What do We Know So Far? J Immunol Res (2015) (1):1-8. doi: 10.1155/2015/979167

31. Moon S, Kim MJ, Yu JM, Yoo HJ, Park YJ. Subclinical Hypothyroidism and the Risk of Cardiovascular Disease and All-Cause Mortality: A Meta-Analysis of Prospective Cohort Studies. Thyroid (2018) 28(9):1101-10. doi: 10.1089/ thy.2017.0414

32. Zhao M, Tang X, Yang T, Zhang B, Guan Q, Shao S, et al. Lipotoxicity, a Potential Risk Factor for the Increasing Prevalence of Subclinical Hypothyroidism? J Clin Endocrinol Metab (2015) 100(5):1887-94. doi: 10.1210/jc.2014-3987

33. Kim D, Kim W, Joo SK, Bae JM, Kim JH, Ahmed A. Subclinical Hypothyroidism and Low-Normal Thyroid Function are Associated With Nonalcoholic Steatohepatitis and Fibrosis. Clin Gastroenterol Hepatol (2018) 16(1):123-31. doi: 10.1016/j.cgh.2017.08.014

34. Rajiwade SR, Sagili H, Soundravally R, Subitha L. Endocrine Abnormalities in Adolescents With Menstrual Disorders. J Obstet Gynecol India (2018) 68 (1):58-64. doi: 10.1007/s13224-017-1035-y

35. Weghofer A, Barad DH, Darmon S, Kushnir VA, Gleicher N. What Affects Functional Ovarian Reserve, Thyroid Function or Thyroid Autoimmunity? Reprod Biol Endocrinol (2016) 14(1):1-6. doi: 10.1186/s12958-016-0162-0

36. Li J, Liu A, Liu H, Li C, Wang W, Han C, et al. Maternal TSH Levels At First Trimester and Subsequent Spontaneous Miscarriage: A Nested Case-Control Study. Endocr Connect (2019) 8(9):1288-93. doi: 10.1530/EC-19-0316

37. Korevaar TIM, Derakhshan A, Taylor PN, Meima M, Chen L, Bliddal S, et al. Association of Thyroid Function Test Abnormalities and Thyroid Autoimmunity With Preterm Birth: A Systematic Review and MetaAnalysis. JAMA (2019) 322(7):632-41. doi: 10.1001/jama.2019.10931

38. Garber JR, Cobin RH, Gharib H, Hennessey JV, Klein I, Mechanick JI, et al. Clinical Practice Guidelines for Hypothyroidism in Adults: Cosponsored by the American Association of Clinical Endocrinologists and the American Thyroid Association. Thyroid (2012) 22(12):1200-35. doi: 10.1089/ thy.2012.0205

39. Michaelsson LF, Medici BB, la Cour JL, Selmer C, Røder M, Hans Perrild H, et al. Treating Hypothyroidism With Thyroxine/ Triiodothyronine Combination Therapy in Denmark: Following Guidelines or Following Trends? Eur Thyroid J (2015) 4(3):174-80. doi: 10.1159/000437262

40. Panicker V, Saravanan P, Vaidya B, Evans J, Hattersley AT, Frayling TM, et al. Common Variation in the DIO2 Gene Predicts Baseline Psychological WellBeing and Response to Combination Thyroxine Plus Triiodothyronine Therapy in Hypothyroid Patients. J Clin Endocrinol Metab (2009) 94 (5):1623-9. doi: 10.1210/jc.2008-1301

41. Smith RN, Taylor SA, Massey JC. Controlled Clinical Trial of Combined Triiodothyronine and Thyroxine in the Treatment of Hypothyroidism. Br Med J (1970) 4(5728):145-8. doi: 10.1136/bmj.4.5728.145

42. Mateo RCI, Hennessey JV. Thyroxine and Treatment of Hypothyroidism: Seven Decades of Experience. Endocrine (2019) 66(1):10-7. doi: 10.1007/ s12020-019-02006-8

43. Jonklaas J, Bianco AC, Bauer AJ, Burman KD, Cappola AR, Celi FS, et al. Guidelines for the Treatment of Hypothyroidism: Prepared by the American Thyroid Association Task Force on Thyroid Hormone Replacement. Thyroid (2014) 24(12):1670-751. doi: 10.1089/thy.2014.0028

44. Pearce SHS, Brabant G, Duntas LH, Monzani F, Peeters RP, Razvi S, et al. ETA Guideline: Management of Subclinical Hypothyroidism. Eur Thyroid J (2014) 2(4):215-28. doi: 10.1159/000356507 
45. Bizzarri M, Carlomagno G. Inositol: History of an Effective Therapy for Polycystic Ovary Syndrome. Eur Rev Med Pharmacol Sci (2014) 18(13):1896-903.

46. Murthy PPN. Chapter 1 Structure and Nomenclature of Inositol Phosphates, Phosphoinositides, and. Structure (2006). Available at: https://link.springer. com/chapter/10.1007/0-387-27600-9_1.

47. Downes CP, Macphee CH. Myo-Inositol Metabolites as Cellular Signals. Eur J Biochem (1990) 193(1):1-18. doi: 10.1111/j.1432-1033.1990.tb19297.x

48. Clements S. Myo-Inositol Development Content of Common of a High-MyoInositol Foods: Diet1'2. Am J Clin Nutr (2005) 1-14. doi: 10.1093/ajcn/33.9.1954

49. Schlemmer U, Frølich W, Prieto RM, Grases F. Phytate in Foods and Significance for Humans: Food Sources, Intake, Processing, Bioavailability, Protective Role and Analysis. Mol Nutr Food Res (2009) 53:S330-75. doi: $10.1002 / \mathrm{mnfr} .200900099$

50. Holub BJ. The Nutritional Significance, Metabolism, and Function of MyoInositol and Phosphatidylinositol in Health and Disease. Adv Nutr Res (1982) 4:107-41. doi: 10.1007/978-1-4613-9934-6_5

51. Schneider S. Inositol Transport Proteins. FEBS Lett (2015) 589(10):1049. doi: 10.1016/j.febslet.2015.03.012

52. De Grazia S, Carlomagno G, Unfer V, Cavalli P. Myo-Inositol Soft Gel Capsules may Prevent the Risk of Coffee-Induced Neural Tube Defects. Expert Opin Drug Deliv (2012) 9(9):1033-9. doi: 10.1517/17425247.2012.701616

53. Shils ME, Shike M, Ross AC, Caballero BCRJ. Modern Nutrition in Health and Disease. Philadelphia: Lippincott Williams \& Wilkins (2006).

54. Croze ML, Soulage CO. Potential Role and Therapeutic Interests of MyoInositol in Metabolic Diseases. Biochimie (2013) 95(10):1811-27. doi: 10.1016/j.biochi.2013.05.011

55. Papaleo E, Unfer V, Baillargeon JP, Fusi F, Occhi F, De Santis L. Myo-Inositol may Improve Oocyte Quality in Intracytoplasmic Sperm Injection Cycles. A Prospective, Controlled, Randomized Trial. Fertil Steril (2009) 91(5):1750-4. doi: 10.1016/j.fertnstert.2008.01.088

56. Bizzarri M, Fuso A, Dinicola S, Cucina A, Bevilacqua A. Pharmacodynamics and Pharmacokinetics of Inositol(s) in Health and Disease. Expert Opin Drug Metab Toxicol (2016) 12(10):1181-96. doi: 10.1080/17425255.2016.1206887

57. Frej AD, Clark J, Le Roy CI, Lilla S, Thomason PA, Otto GP, et al. The Inositol-3-Phosphate Synthase Biosynthetic Enzyme Has Distinct Catalytic and Metabolic Roles. Mol Cell Biol (2016) 36(10):1464-79. doi: 10.1128/ MCB.00039-16

58. Grafton G, Baxter MA, Sheppard MC, Eggo MC. Regulation of Myo-Inositol Transport During the Growth and Differentiation of Thyrocytes: A Link With Thyroid-Stimulating Hormone-Induced Phospholipase A2 Activity. Biochem $J$ (1995) 309(2):667-75. doi: 10.1042/bj3090667

59. Field JB, Ealey PA, Marshall NJ, Cockcroft S. Thyroid-Stimulating Hormone Stimulates Increases in Inositol Phosphates as Well as Cyclic AMP in the FRTL-5 Rat Thyroid Cell Line. Biochem J (1987) 247(3):519-24. doi: 10.1042/bj2470519

60. Chen G, Pekary AE, Sugawara M, Hershman JM. Effect of Exogenous Hydrogen Peroxide on Iodide Transport and Iodine Organification in FRTL-5 Rat Thyroid Cells. Acta Endocrinol (1993) 129:89-96. doi: 10.1530/acta.0.1290089

61. Fong P. Thyroid Iodide Efflux: A Team Effort? J Physiol (2011) 589(Pt 24):592939. doi: 10.1113/jphysiol.2011.218594. doi: 10.1113/jphysiol.2011.218594.

62. Pace C, Tumino D, Russo M, Le Moli R, Naselli A, Borzì G, et al. Role of Selenium and Myo-Inositol Supplementation on Autoimmune Thyroiditis Progression. Endocr J (2020) 67(11):1093-8. doi: 10.1507/endocri.EJ20-0062

63. Nordio M, Pajalich R. Combined Treatment With Myo-Inositol and Selenium Ensures Euthyroidism in Subclinical Hypothyroidism Patients With Autoimmune Thyroiditis. J Thyroid Res (2013) 5. doi: 10.1155/2013/424163

64. Morgante G, Musacchio MC, Orvieto R, Massaro MG, De Leo V. Alterations in Thyroid Function Among the Different Polycystic Ovary Syndrome
Phenotypes. Gynecol Endocrinol (2013) 29(11):967-9. doi: 10.3109/ 09513590.2013.829445

65. Nordio M, Basciani S. Treatment With Myo-Inositol and Selenium Ensures Euthyroidism in Patients With Autoimmune Thyroiditis. Int J Endocrinol (2017) (13):1-6. doi: 10.1155/2017/2549491

66. Nordio M, Basciani S. Myo-Inositol Plus Selenium Supplementation Restores Euthyroid State in Hashimoto's Patients With Subclinical Hypothyroidism. Eur Rev Med Pharmacol Sci (2017) 21(2):51-9. doi: 10.1155/2017/2549491

67. Ferrari SM, Fallahi P, Di Bari F, Vita R, Benvenga S, Antonelli A. Myo-Inositol and Selenium Reduce the Risk of Developing Overt Hypothyroidism in Patients With Autoimmune Thyroiditis. Eur Rev Med Pharmacol Sci (2017) 21(2):36-42.

68. Porcaro G, Angelozzi P. Myo-Inositol and Selenium Prevent Subclinical Hypothyroidism During Pregnancy: An Observational Study. Obstetric (2018) 1(2):e164.

69. Briguglia G. Time-Dependent Efficacy of Myo-Inositol Plus Selenium in Subclinical Hypothyroidism. Int J Med Device Adjuv Treat (2018) 1(1):e108.

70. Fallahi P, Ferrari SM, Elia G, Ragusa F, Paparo SR, Caruso C, et al. MyoInositol in Autoimmune Thyroiditis, and Hypothyroidism. Rev Endocr Metab Disord (2018) 19(4):349-54. doi: 10.1007/s11154-018-9477-9

71. Benvenga S, Vicchio T, Di Bari F, Vita R, Fallahi P, Ferrari SM, et al. Favorable Effects of Myo-Inositol, Selenomethionine or Their Combination on the Hydrogen Peroxide-Induced Oxidative Stress of Peripheral Mononuclear Cells From Patients With Hashimoto's Thyroiditis: Preliminary In Vitro Studies. Eur Rev Med Pharmacol Sci (2017) 21(2):89-101.

72. Ruffilli I, Ferrari SM, Colaci M, Ferri C, Politti U, Antonelli A, et al. CXCR3 E CXCL10 Nella Tiroidite Autoimmune. Clin Ter (2014) 165(3):e237-42. doi: 10.7417/CT.2014.1727

73. Ferrari SM, Elia G, Ragusa F, Ruffilli I, Paparo SR, Caruso C, et al. MyoInositol and Selenium in Subclinical Hypothyroidism. Int J Med Device Adjuv Treat (2018) 1:e166.

74. Deja S, Dawiskiba T, Balcerzak W, Orczyk-Pawiłowicz M, Głód M, Pawełka D, et al. Follicular Adenomas Exhibit a Unique Metabolic Profile.1H Nmr Studies of Thyroid Lesions. PloS One (2013) 8(12):1-13. doi: 10.1371/ journal.pone.0084637

75. Gharib H, Papini E, Garber JR, Duick DS, Harrell RM, Hegedüs L, et al. American Association of Clinical Endocrinologists, American College of Endocrinology, and Associazione Medici Endocrinologi Medical Guidelines for Clinical Practice for the Diagnosis and Management of Thyroid Nodules 2016 Update. Endocr Pract (2016) 22:1-60. doi: 10.4158/EP.12.1.63

76. Nordio M, Basciani S. Evaluation of Thyroid Nodule Characteristics in Subclinical Hypothyroid Patients Under a Myo-Inositol Plus Selenium Treatment. Eur Rev Med Pharmacol Sci (2018) 22(7):2153-9. doi: 10.26355/ eurrev_201804_14749

Conflict of Interest: VU is an employee at Lo.Li Pharma s.r.l., Rome (Italy).

The remaining authors declare that the research was conducted in the absence of any commercial or financial relationships that could be construed as a potential conflict of interest.

Copyright (c) 2021 Benvenga, Nordio, Laganà and Unfer. This is an open-access article distributed under the terms of the Creative Commons Attribution License (CC BY). The use, distribution or reproduction in other forums is permitted, provided the original author(s) and the copyright owner(s) are credited and that the original publication in this journal is cited, in accordance with accepted academic practice. No use, distribution or reproduction is permitted which does not comply with these terms. 